\title{
Neurobehavioral evaluation of high blood pressure and low blood pressure mice
}

\author{
S. THIFAULT, R. LALONDE, C. C. JOYAL, and P. HAMET \\ Centre hospitalier de l'Université de Montréal, Montréal, Québec, Canada
}

\begin{abstract}
Mice chronically subjected to high blood pressure (HBP) or to low blood pressure (LBP) were compared with normotensive controls in tests of exploration, motor coordination, and spatial learning at two age levels: young adult ( 3 months) and middle-aged ( 12 months). At either age, by comparison with controls, HBP mice were hyperactive in an open field, but not in terms of hole-poking responses. On the contrary, LBP mice were hypoactive in the open field and in the hole board, with the effect on the former measure being limited to the younger cohort. In either cohort, HBP and LBP mice were deficient in some aspects of sensorimotor testing requiring balance and equilibrium. Moreover, HBP and LBP mice had longer path lengths and escape latencies during acquisition of a hidden platform in a water maze. In the younger cohort, LBP mice had longer path lengths and escape latencies, even during a visible platform version of the task, an indication of a disturbed visuomotor function. These mutants may serve as experimental models for the evaluation of beneficial antihypertensive or antihypotensive treatments on brain function.
\end{abstract}

Although in Western countries hypertension is generally controlled by available antihypertensive drugs, there is an interest in developing animal models of chronic hypertension, in order to compare between the potentially beneficial effects of these agents on brain functions. Many hypertensive strains of rats are available (McCarty, 1983), but the behavior of spontaneously hypertensive rats (SHRs), which can serve as an experimental model of essential hypertension in humans (Yamori, 1983), has been the most thoroughly studied. It has frequently been reported that the motor activity of SHRs is higher than that of the Wistar Kyoto control strain (Gentsch, Lichtsteiner, \& Feer, 1987; Leaton, Cassella, \& Whitehorn, 1983; Sagvolden, Hendley, \& Knardahl, 1992; Whitehorn, Atwater, Low, Gellis, \& Hendley, 1983) and of other strains, such as the Wistar (Danysz et al., 1983). However, the increase of motor activity and the increase of arterial pressure in SHRs are caused by independent genes (Sagvolden et al., 1992; Whitehorn et al., 1983).

In addition to changes in motor activity, learning deficits have been reported in SHRs, in some but not all tasks. For example, Knardahl and Karlsen (1984) found that SHRs had more entries into shocked areas than Wistar Kyoto rats in a multiple-trial passive avoidance task under different stimulus discriminability conditions. Moreover, SHRs were impaired during the acquisition of a barpress response (Meneses \& Hong, 1998). However, other reports

Supported in part by the Medical Research Council of Canada (MT14654). S.T. received a doctoral scholarship from the Canadian Heart and Stroke Foundation. Correspondence concerning this article should be addressed to P. Hamet, Centre de recherche, Centre hospitalier de l'Université de Montréal-Hôtel-Dieu, Laboratoire de Pathophysiologie Moléculaire de 1'Hypertension, 3850, rue St-Urbain, Montréal, PQ, H2W IT8, Canada (e-mail: hamet@ere.umontreal.ca). have indicated not only a lack of a deficit, but even a paradoxical improvement (Danysz et al., 1983; WidyTyszkiewicz, Scheel-Krüger, \& Christensen, 1993). One factor that may explain these differential results is the age of the animals. The acquisition of an eight-arm radial maze task was impaired in SHRs, by comparison with Sprague-Dawley rats, at 12 months, but not at 3 months of age (Wyss, Fisk, \& van Groen, 1992). The latter result may be due to age-associated brain abnormalities (Bendel \& Eilam, 1992; Ritter \& Dinh, 1986) or retinopathy (Saito et al., 1992) as a direct consequence of chronic exposure to hypertension. On the other hand, ventricle volume dilation was not reversed by early administration of captopril, an angiotensin-converting enzyme inhibitor and antihypertensive agent (Ritter, Dinh, Stone, \& Ross, 1988), indicating that some indices of brain atrophy in SHRs are independent of arterial pressure.

The present study describes the behavioral characteristics of a second model of hypertension, high blood pressure (HBP) mice, which can be compared either with normotensive mice or with low blood pressure (LBP) mice (Schlager, 1974; Schlager, Freeman, \& Sustartic, 1979). These lines were obtained from crossbreeding eight unrelated inbred strains, followed by random mating with a randomly bred normotensive control group, yielding, by the 24th generation, HBP mice with mean blood pressure levels of $142 \mathrm{~mm} \mathrm{Hg}$, normotensive mice with levels of $102 \mathrm{~mm} \mathrm{Hg}$, and LBP mice with levels of $81 \mathrm{~mm} \mathrm{Hg}$ (Iwao et al., 1984; Schlager, 1981). By the 37th generation, sufficient to fix the genes in each line, the mean BP values of the 3-month-old HBP group (132 $\mathrm{mm} \mathrm{Hg}$ ) were significantly higher than those of the age-matched normotensive group (96 mg Hg; Malo, Schlager, Tremblay, \& Hamet, 1989). Similar values were reported in a subsequent study (Malo, Pang, Schlager, Tremblay, \& Hamet, 1990). 
Differences in brain neurotransmitter levels have been reported between these strains. HBP mice had higher whole-brain concentrations of noradrenaline, whereas LBP mice had lower levels (Schlager et al., 1979). These brain abnormalities may be directly responsible for their altered blood pressure levels, as this neurotransmitter has been shown to be involved in altered responses to stress (Henry, Liu, \& Meehan, 1995). Since apoptotic cell death in widespread regions of the brain (neocortex, striatum, hippocampus, thalamus) and other organs has been described in HBP mice at 12 months of age (Hamet et al., 1995), we decided to evaluate their behavioral characteristics at that age with a battery made up of a wide range of functions, including motor activity, motor coordination, and spatial learning. As a basis of comparison, a separate series of mice were evaluated at the young adult stage ( 3 months of age). We wished to determine whether HBP mice are hyperactive, as has been reported in SHRs. We also wished to determine whether HBP mice have defects in tasks requiring balance and equilibrium and in a water maze task (Goodlett, Hamre, \& West, 1992; Lalonde, 1987; Lines \& Milner, 1985; Morris, Garrud, Rawlins, \& O'Keefe, 1982; Sutherland \& Rodriguez, 1989).

Untreated hypertension can lead to cerebrovascular disease and neuropsychological deficits, but the possible neuropsychological consequences of hypotension have not, to our knowledge, been investigated in human patients. Primary orthostatic hypotension appears in several syndromes and as a consequence of central and peripheral nervous system disorders or drug ingestion (Stewart, Bray, \& Aguayo, 1983). In the present study, the neurobehavioral effects of chronic hypotension were directly compared with the effects of hypertension.

\section{METHOD}

\section{Animals}

In the first experiment, HBP mice ( $n=6)$, LBP mice $(n=5)$, and normotensive controls $(n=8)$, originally obtained from the laboratory of G. Schlager, were used. These mice were bred in our laboratory on the basis of brother-sister matings and were approximately 12 months of age at the start of testing. In the second experiment, 3-month-old mice were used: HBP mice $(n=11)$, LBP mice $(n=$ 5 ), and controls $(n=12)$. At no age did any mice display overt signs of neurological dysfunction. The mice in both experiments were evenly distributed in terms of sex (approximately $60 \%$ male, $40 \%$ female). The mice were kept in group cages with bedding made of wood shavings in a temperature- and humidity-controlled room, with behavioral evaluations taking place in a separate room.

\section{Apparatus}

A transparent plastic T-maze (stem, $22 \times 8.5 \mathrm{~cm}$; arms, $30 \times$ $8.5 \mathrm{~cm}$; wall height, $10 \mathrm{~cm}$ ) was used for spontaneous alternation testing. Motor activity was measured in a white opaque plastic chamber $(30 \times 25 \mathrm{~cm}$; wall height, $15 \mathrm{~cm})$, whose floor was separated by felt pen markings into six equally spaced segments. Hole poking was evaluated in a circular blue opaque plastic chamber (diameter, $30 \mathrm{~cm}$ ) suspended at a height of $60 \mathrm{~cm}$ from the floor. There were four holes in the periphery and one hole in the center. Each hole had a diameter of $2.5 \mathrm{~cm}$, and the interhole distance was $10 \mathrm{~cm}$.

Motor coordination was evaluated by means of an inclined grid, a coat hanger, and a round bridge. The grid $(38 \times 38 \mathrm{~cm}$, five squares $/ \mathrm{cm}$ ) was surrounded by a wooden frame and inclined at $45^{\circ}$. The coat hanger was made of steel and was triangular in shape. The horizontal bar of the coat hanger, placed at a height of $85 \mathrm{~cm}$ from a cushion-covered table, measured $40 \mathrm{~cm}$ in length and $2 \mathrm{~mm}$ in diameter, flanked by two diagonal bars, $19 \mathrm{~cm}$ in length and with an inclination of $35^{\circ}$. The round metal bridge (diameter, $2 \mathrm{~cm}$ ), placed at a height of $85 \mathrm{~cm}$, measured $110 \mathrm{~cm}$ in length and was separated into 11 equally spaced segments by means of a felt pen. The diameter was $20 \mathrm{~cm}$. Either end was blocked by a barrier made of cardboard, in order to prevent any escape.

Spatial learning was evaluated in an opaque plastic basin $(61 \times$ $40 \mathrm{~cm}$; wall height, $22 \mathrm{~cm})$ filled with a milky solution $\left(27^{\circ} \mathrm{C}\right)$ and containing a platform, $6.5 \mathrm{~cm}$ in diameter, placed $1.5 \mathrm{~cm}$ below water level and covered by wire mesh for firm gripping. The height between the water level and the wall was $13 \mathrm{~cm}$, permitting the mice to see some of the room cues available. The pool remained in the same position, relative to the room cues, such as various pieces of laboratory equipment and a window. The experimenter remained in the same position on every trial.

\section{Procedure}

Spontaneous alternation was evaluated on Days 1-12. The inclined grid was performed on Days $1-3$, motor activity on Days $4-6$, the coat hanger on Days 7-9, and the round bridge on Days 10-12. Acquisition of the water maze hidden platform task was evaluated on Days 14-18, retention on Day 25, and visible platform training on Day 26. Hole poking was assessed on Days 22-23.

A two-trial paradigm was adopted for spontaneous alternation. On Day 1, the mice were placed in the stem of the T-maze, with the left arm being blocked by a plastic barrier. After turning to the right, the mice were kept in the arm for $1 \mathrm{~min}$, after which time they were removed and placed in a plastic container for the brief period necessary to wash and dry the maze. During the test trial, they could choose either the same arm or an alternate (four-paw criterion). The arm chosen to be blocked was changed from one day to the next (left for odd-numbered and right for even-numbered days). Retention time was 0 min on Days 1, 4, 7, and 10,3 min on Days 2, 5, 8, and 11, and $10 \mathrm{~min}$ on Days 3,6,9, and 12. During the 3-and 10-min retention intervals, the animals were returned to their home cage.

On Days 1-3, after spontaneous alternation testing, the mice were placed in the middle of the inclined grid, facing downward. Three measures were recorded: the elapsed times (1) before the mice turned $180^{\circ}$ to face upward (turn latencies), (2) before they reached, according to the snout criterion, the top of the grid (top latencies), and (3) before they fell from the grid (fall latencies). One trial was conducted per day, with a cutoff period of $1 \mathrm{~min}$ per trial.

On Days 4-6, the number of segment crossings (four-paw criterion) in the activity chamber was measured for 4 min per day. On Days 7-9, the mice were placed in the middle of the horizontal bar of the coat hanger in an upside-down position, with care being taken

Table 1

Mean Two-Trial Spontaneous Alternation Percentages and Mean Choice Latencies (in Seconds; With Standard Errors) Summed Over Days in a T-maze

\begin{tabular}{|c|c|c|c|c|c|}
\hline \multirow[b]{2}{*}{ Group } & \multicolumn{3}{|c|}{ Retention Interval (min) } & \multicolumn{2}{|c|}{ Latency } \\
\hline & 0 & 3 & 10 & $M$ & $S E$ \\
\hline \multicolumn{6}{|l|}{12 month old } \\
\hline High blood pressure & 54 & 46 & 50 & 116 & $25 \dagger$ \\
\hline Low blood pressure & 40 & 30 & 55 & 638 & 33 \\
\hline Control & 59 & 59 & 63 & 455 & 56 \\
\hline \multicolumn{6}{|l|}{3 month old } \\
\hline High blood pressure & $61^{*}$ & 56 & 30 & 50 & $8+$ \\
\hline Low blood pressure & 50 & 35 & 50 & 542 & $41+$ \\
\hline Control & $71^{*}$ & $65^{*}$ & 56 & 165 & 24 \\
\hline
\end{tabular}


Table 2

Mean Latencies (With Standard Errors) in Seconds Before Turning, Reaching the Top, and Falling on an Inclined Grid, Summed Over Days

\begin{tabular}{|c|c|c|c|c|c|c|}
\hline \multirow[b]{2}{*}{ Group } & \multicolumn{2}{|c|}{ Turn } & \multicolumn{2}{|c|}{ Top } & \multicolumn{2}{|c|}{ Fall } \\
\hline & $M$ & $S E$ & $M$ & $S E$ & $M$ & $S E$ \\
\hline \multicolumn{7}{|l|}{12 month old } \\
\hline High blood pressure & 31 & 6 & $49 \dagger$ & 10 & 180 & 0 \\
\hline Low blood pressure & 35 & 8 & 137 & 18 & 180 & 0 \\
\hline Control & 43 & 12 & 117 & 18 & 180 & 0 \\
\hline \multicolumn{7}{|l|}{3 month old } \\
\hline High blood pressure & 20 & 3 & 57 & 10 & 180 & 0 \\
\hline Low blood pressure & $53 \dagger$ & 11 & $124^{*}$ & 17 & 180 & 0 \\
\hline Control & 16 & 2 & 69 & 10 & 180 & 0 \\
\hline
\end{tabular}

${ }^{*} p=.05$ versus controls. ${ }^{\dagger} p<.01$ versus controls.

that all four paws gripped the bar at the moment of release. The measures recorded were the elapsed time before reaching either sidebar, with two-, three-, or four-paw criteria, together with latencies before falling (cutoff, $1 \mathrm{~min}$ ), and the number of occasions when the halfway part or the top of the diagonal bar was reached. The animal was removed after reaching the top, and a score of $60 \mathrm{sec}$ was given for the fall latency. There were two trials per day, with an intertrial interval of approximately $15 \mathrm{~min}$.

On Days 10-12, the mice were placed in the middle of the round bridge. The time spent on the bridge before falling (cutoff, $1 \mathrm{~min}$ ) and the number of segments traversed were tabulated for three trials per day, with an intertrial interval of $15 \mathrm{~min}$.

On Days 14-18, the mice were placed in the water basin near and facing the southern (S) wall. The number of quadrants traversed and the escape latencies (cutoff, $1 \mathrm{~min}$ ) before reaching the hidden platform were counted. After $1 \mathrm{~min}$, mice unable to find the platform were removed from the water and placed on it for $5 \mathrm{sec}$. On Trials $2-4$, the mice were placed in the west, north, and east positions, in that order, with the position of the platform kept in the northwest quadrant. There were two blocks of four trials each. The intertrial interval within a block was $10 \mathrm{~min}$, and between blocks it was $30 \mathrm{~min}$. After the last day of acquisition, a retention test was given on Day 25 under identical conditions, but with only one block of four trials. The visible platform test was performed on Day 26 with six trials, when the platform was lifted above water level and moved toward the northeast quadrant. At that time, the basin contained clear water.

On Days 22-23, the mice were put in the hole board, and the number of pokes in the periphery and the center of the board were counted for 3 min per day.

\section{Statistical Analyses}

Analyses of variance (ANOVAs), with repeated measures and the Dunnett $t$ test for multiple comparisons, were used. Time-dependent measures were $\log$ transformed, because of the heterogeneous variances. The Mann-Whitney $U$ test was used to evaluate significance of the alternation rate above chance.

\section{RESULTS}

\section{Spontaneous Alternation}

In 3-month-old mice, there were significant main factor effects only $[F(2,25)=3.76, p<.05$, for the group, and $F(2,50)=4.6, p<.05$, for the interval]. The alternation rate of the normotensive controls was higher than that of both experimental groups, and this rate decreased as the retention interval increased for all three groups (Table 1). The control mice alternated above chance at retention intervals of $0[z=2.81, p<.01]$ and $3[z=2.83$, $p<.01] \mathrm{min}$, but not at $10 \mathrm{~min}(p>.05)$. On the contrary, the LBP mice did not alternate above chance at any interval. The HBP mice alternated above chance only at the 0 -min interval $[z=2.14, p<.05]$. A significant group effect was observed for choice latencies $[F(2,27)=$ $44.68, p<.001]$, since the HBP mice had lower choice latencies than did the controls $[t(2,25)=5.59, p<.01]$, which in turn had lower latencies than did the LBP mice $[t(2,25)=4.97, p<.01]$.

In 12-month-old mice, there were no significant effects, in terms of number of alternations, for group $[F(2,16)=$ $2.42, p>.1]$ and interval $[F(2,32)=1.02, p>.1]$ main factors or for the interaction $[F(4,32)=0.65, p>.1]$. None of the groups alternated above chance at any retention interval ( $p>.05$; Table 1). On the contrary, a significant group effect was observed for choice latencies $[F(2,18)=29.49, p<.001]$. The HBP mice had lower choice latencies than did the normotensive mice $[t(2,16)=$ $6.19, p<.01]$, but the latter did not differ from the LBP mice $[t(2,16)=1.64, p>.05]$.

\section{Inclined Grid}

In 3-month-old mice, significant group effects occurred for turn latencies $[F(2,27)=10.41, p<.001]$ and top latencies $[F(2,27)=4.56, p<.05]$, but not for fall la-

Table 3

Mean Latencies in Seconds Before Reaching the Diagonal Bar According to Two-, Three-, or Four-Paw Criteria, Latencies Before Falling, and Frequencies of Reaching the Halfway Point or the Top of the Bar on the Coat Hanger (With Standard Errors)

\begin{tabular}{|c|c|c|c|c|c|c|c|c|c|c|c|c|}
\hline \multirow[b]{2}{*}{ Group } & \multicolumn{2}{|c|}{ Two-paw } & \multicolumn{2}{|c|}{ Three-paw } & \multicolumn{2}{|c|}{ Four-paw } & \multicolumn{2}{|c|}{ Halfway } & \multicolumn{2}{|c|}{ Top } & \multicolumn{2}{|c|}{ Fall } \\
\hline & $M$ & $S E$ & $M$ & $S E$ & $M$ & $S E$ & $M$ & $S E$ & $M$ & $S E$ & $M$ & $S E$ \\
\hline \multicolumn{13}{|l|}{12 month old } \\
\hline High blood pressure & $297 \dagger$ & 25 & $324 \dagger$ & 18 & $330 t$ & 18 & $1.0+$ & 0.7 & $1.0 \dagger$ & 0.6 & 287 & 24 \\
\hline Low blood pressure & $213+$ & 31 & $310+$ & 31 & $319 \dagger$ & 24 & $0.8 \dagger$ & 0.5 & $0.4 \dagger$ & 0.2 & 319 & 24 \\
\hline Control & 101 & 22 & 170 & 19 & 184 & 21 & 4.0 & 0.3 & 4.0 & 0.5 & 312 & 18 \\
\hline \multicolumn{13}{|l|}{3 month old } \\
\hline High blood pressure & $265+$ & 24 & $284^{*}$ & 21 & $295^{*}$ & 18 & $1.0 \dagger$ & 0.3 & $0.2 \dagger$ & 0.1 & 359 & 1 \\
\hline Low blood pressure & 201 & 48 & 271 & 41 & 286 & 39 & $2.0^{*}$ & 1.0 & $1.0 \dagger$ & 1.0 & $280 \dagger$ & 35 \\
\hline Control & 149 & 20 & 184 & 22 & 200 & 23 & 4.0 & 0.4 & 3.0 & 0.5 & 358 & 2 \\
\hline
\end{tabular}



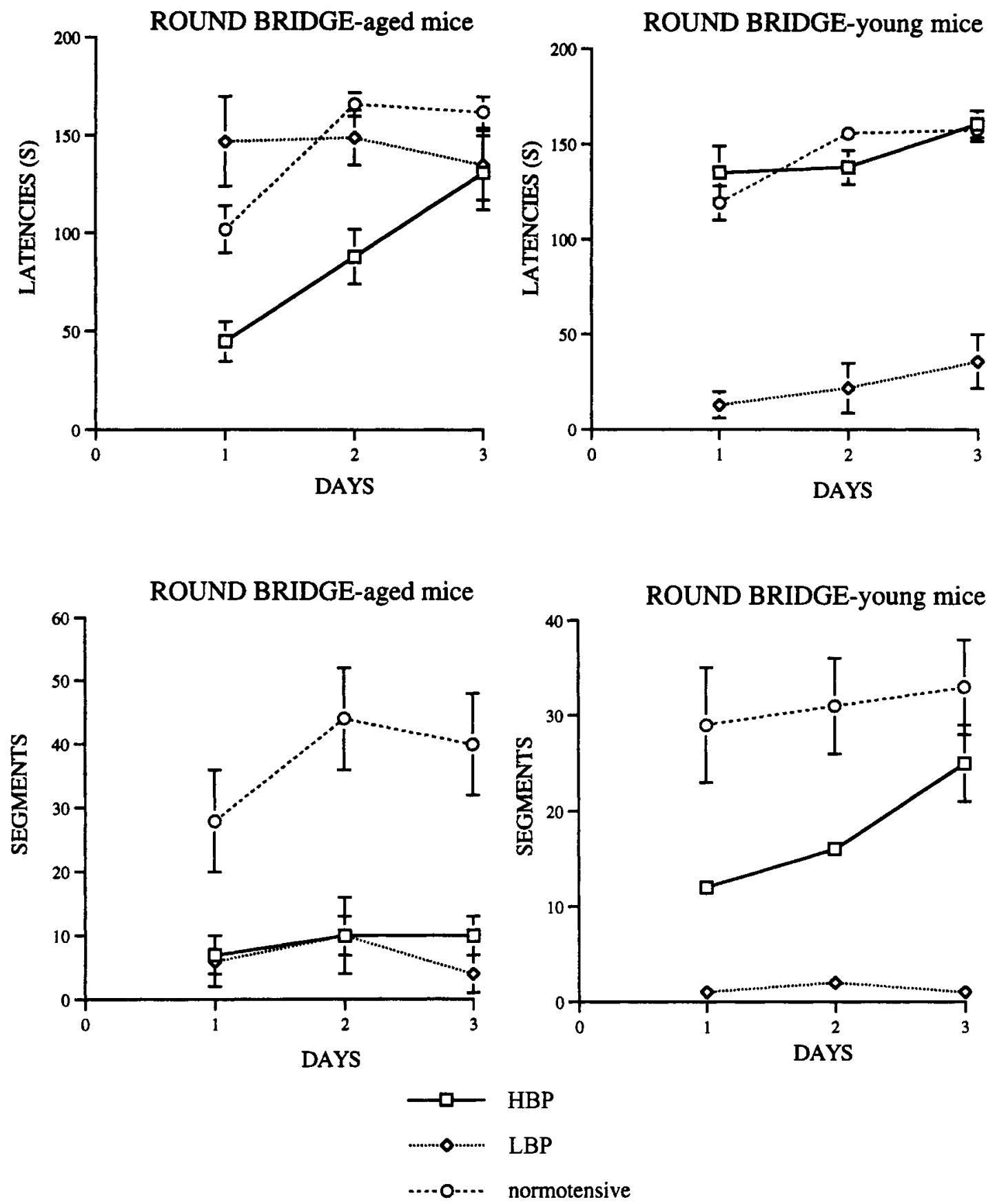

Figure 1. Latencies before falling, in seconds, and segments (means and standard errors) traversed on the round bridge in aged and young cohorts. HBP, high blood pressure; LBP, low blood pressure.

tencies, since no mice fell off the grid (Table 2). The LBP mice were slower before turning upward than were the controls $(p<.01)$. They were also slower before reaching the top $(p=.05)$. The HBP mice had normal values on these two measures $(p>.05)$.

In 12-month-old mice, significant group effects occurred for top latencies $[F(2,18)=9.32, p<.01]$, but not for turn latencies $[F(2,18)=0.17, p>.1]$ or fall latencies, since no mice fell off the grid (Table 2). The HBP mice took less time before reaching the top of the grid than did the controls $(p<.01)$, whereas the LBP mice did not differ from controls $(p>.05)$.

\section{Coat Hanger}

In 3-month-old mice, there were significant group effects for all six measures, according to one-way ANOVAs $(p<.05)$. The HBP mice, but not the LBP mice, had higher latencies before reaching the sidebar according to 
all the paw criteria $(p<.05$; Table 3 ). On the other hand, the LBP mice, but not the HBP mice, fell off the apparatus more quickly than did normotensive mice $(p<.01)$. Both the HBP and the LBP mice reached the halfway point $(p<.05)$ or the top of the diagonal bar less frequently than did the controls $(p<.01)$.

In 12-month-old mice, there were significant group effects for five out of the six measures, according to oneway ANOVAs $(p<.001)$. The HBP and LBP mice had higher latencies before reaching the sidebar than did the controls, according to all the paw criteria $(p<.01$;
Table 3). In addition, the HBP and the LBP mice reached the halfway point or the top of the diagonal bar less frequently than did the controls $(p<.01)$. However, there was no intergroup difference in terms of latencies before falling $[F(2,18)=0.59, p>.1]$.

\section{Round Bridge}

In 3-month-old mice, a significant group effect on latencies before falling (Figure 1 ) was revealed $[F(2,25)=$ $52.08, p<.001]$. The same pattern emerged for segments crossed $(p<.05)$. The LBP mice fell more quickly and
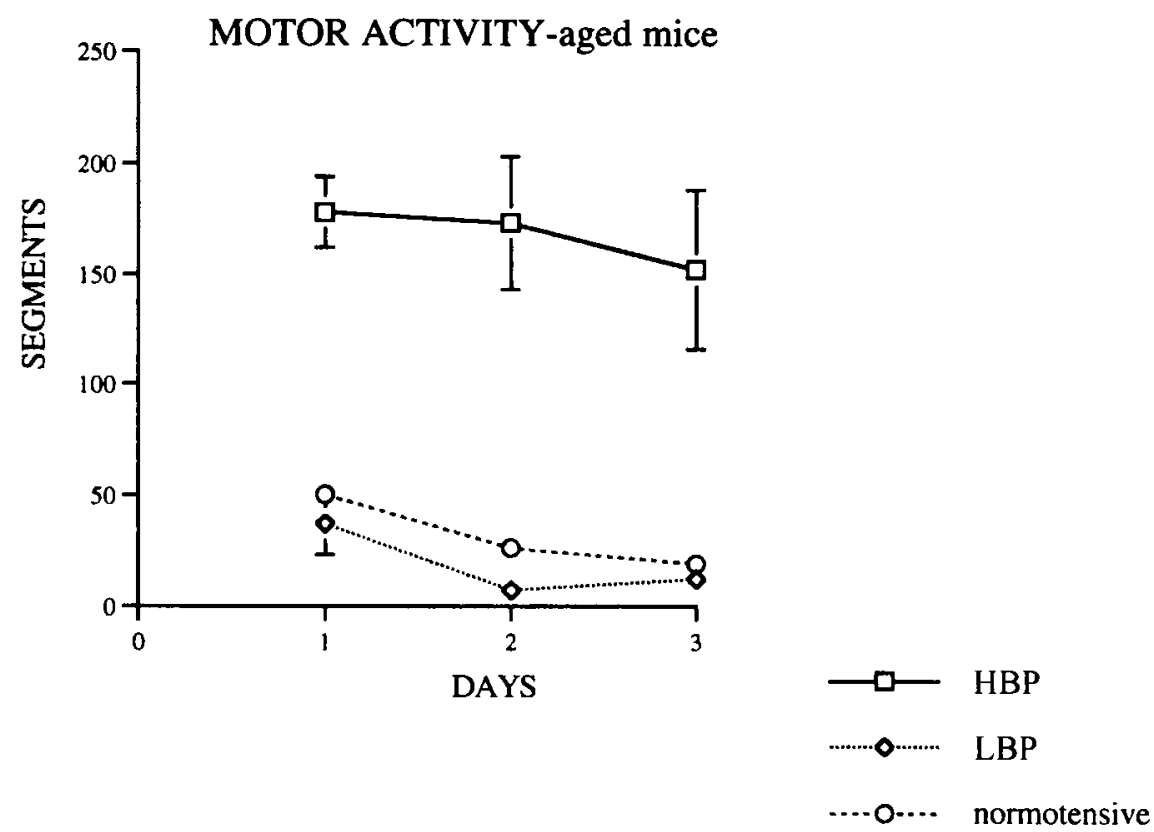

MOTOR ACTIVITY-young mice

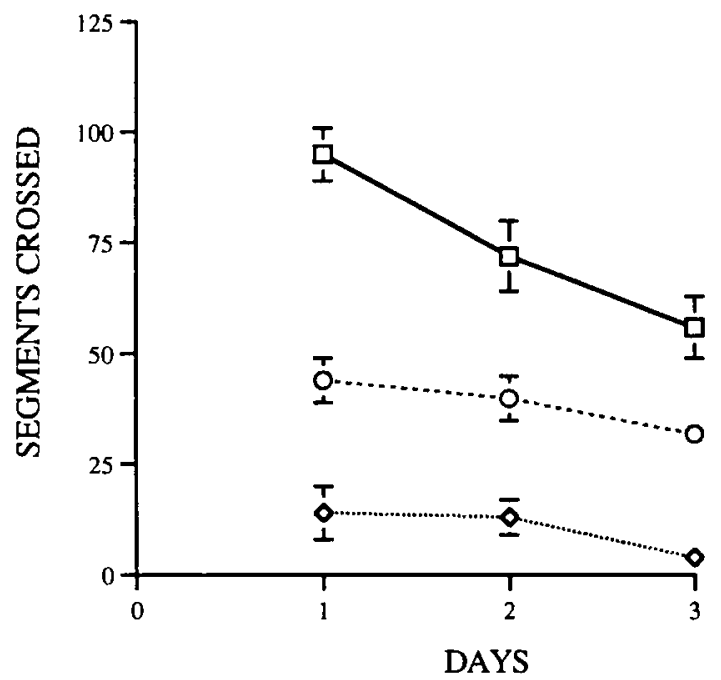

Figure 2. Horizontal motor activity (means and standard errors) of aged and young cohorts. HBP, high blood pressure; LBP, low blood pressure. 
crossed fewer segments than did the controls $(p<.01)$, whereas the HBP mice had normal fall latencies $(p>.05)$ but crossed fewer segments $(p<.05)$.

In 12-month-old mice, a significant group effect was found for latencies before falling [Figure $1 ; F(2,16)=9.89$, $p<.01]$, together with a day effect $[F(2,32)=3.69, p<$
$.05]$, in the absence of an interaction $[F(4,32)=1.23, p>$ .1]. The HBP mice fell more quickly from the beam than did the normotensive mice $(p<.01)$. This was not the case for the LBP mice $(p>.1)$. Latencies increased across days of testing (Figure 1). For segments crossed, the interaction was significant $(p<.01)$. The HBP mice

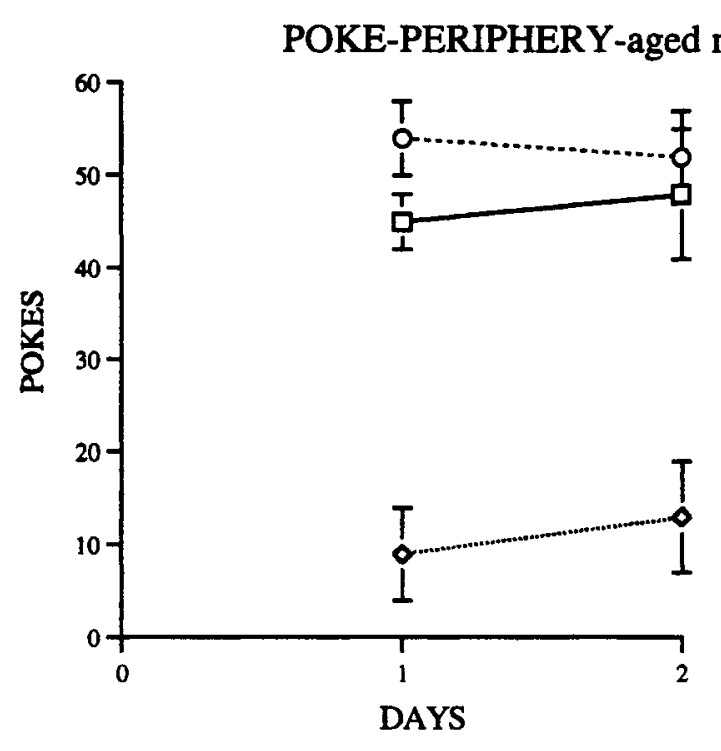

POKE-CENTER-aged mice

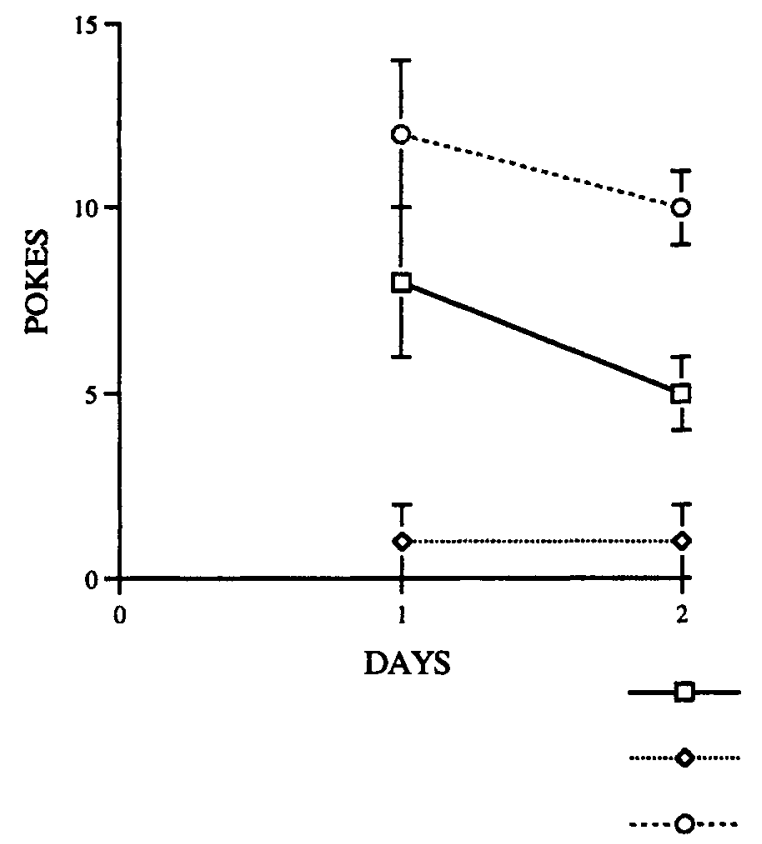

POKE-PERIPHERY-young mice

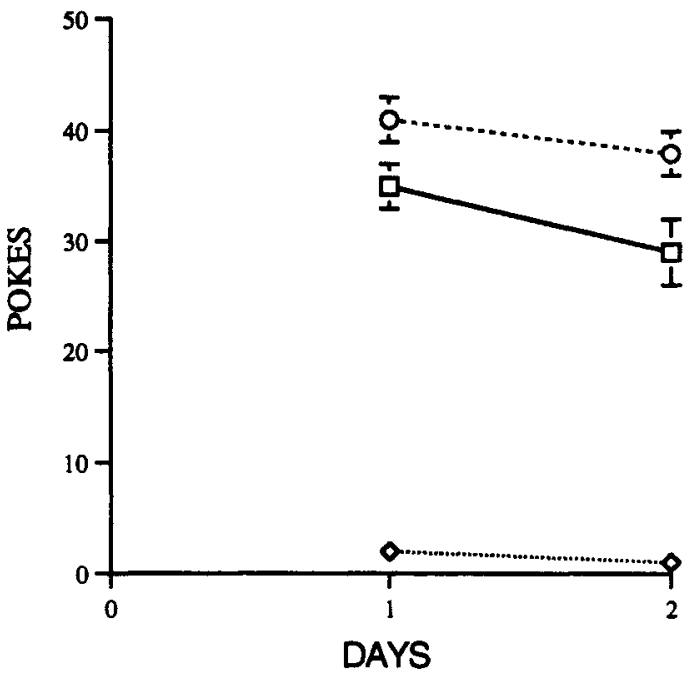

POKE-CENTER-young mice

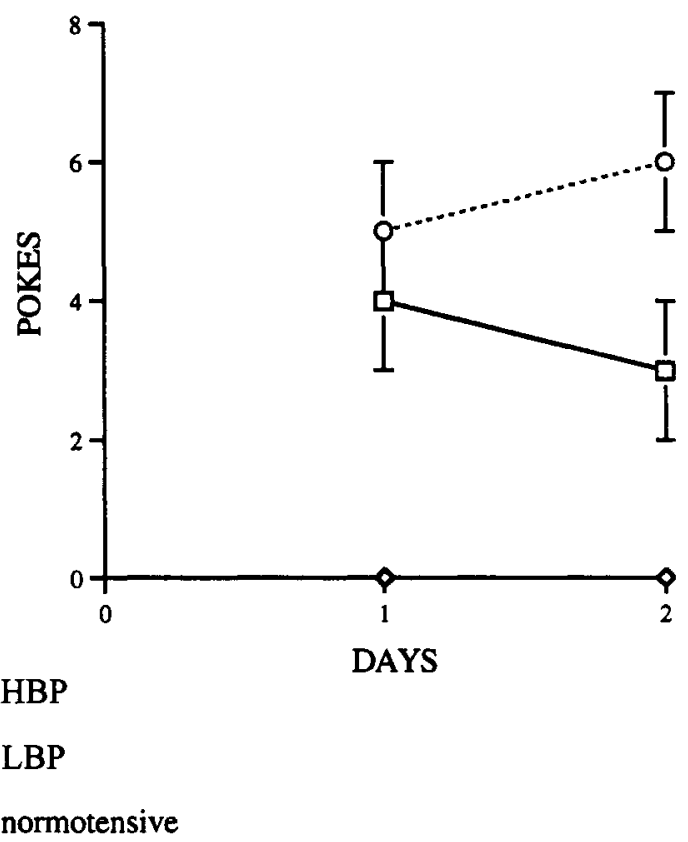

Figure 3. Hole poking (means and standard errors) in the periphery and in the center of the hole board of aged and young cohorts. HBP, high blood pressure; LBP, low blood pressure. 
crossed fewer segments than did the normotensive mice on Days 2 and $3(p<.01)$, but not on Day 1 . The LBP mice crossed fewer segments only on Day $2(p<.01)$.

\section{Motor Activity}

In 3-month-old mice, a significant interaction was observed $(p<.01)$. By comparison with the normotensive controls, the HBP mice crossed more segments $(p<.01)$, whereas the LBP mice crossed fewer segments $(p<.05)$, the difference being more evident on the 1 st day of testing (Figure 2).

In 12-month-old mice, there were significant effects for both main factors $[F(2,16)=38.35, p<.001$, for group, and $F(2,32)=4.23, p<.05$, for day], but not for the interaction $[F(4,32)=0.36, p>.1]$. By comparison with the controls, the HBP mice crossed more segments $(p<$ $.01)$. On the contrary, the LBP mice did not differ from the controls $(p>.05 ;$ Figure 2$)$. All three groups had lower

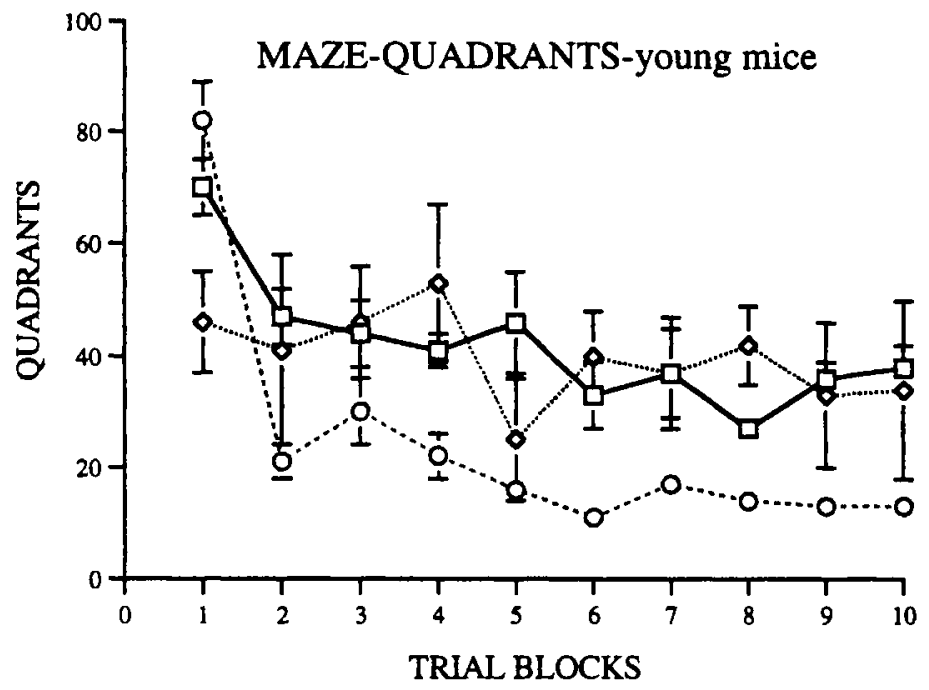

MAZE-LATENCIES-young mice
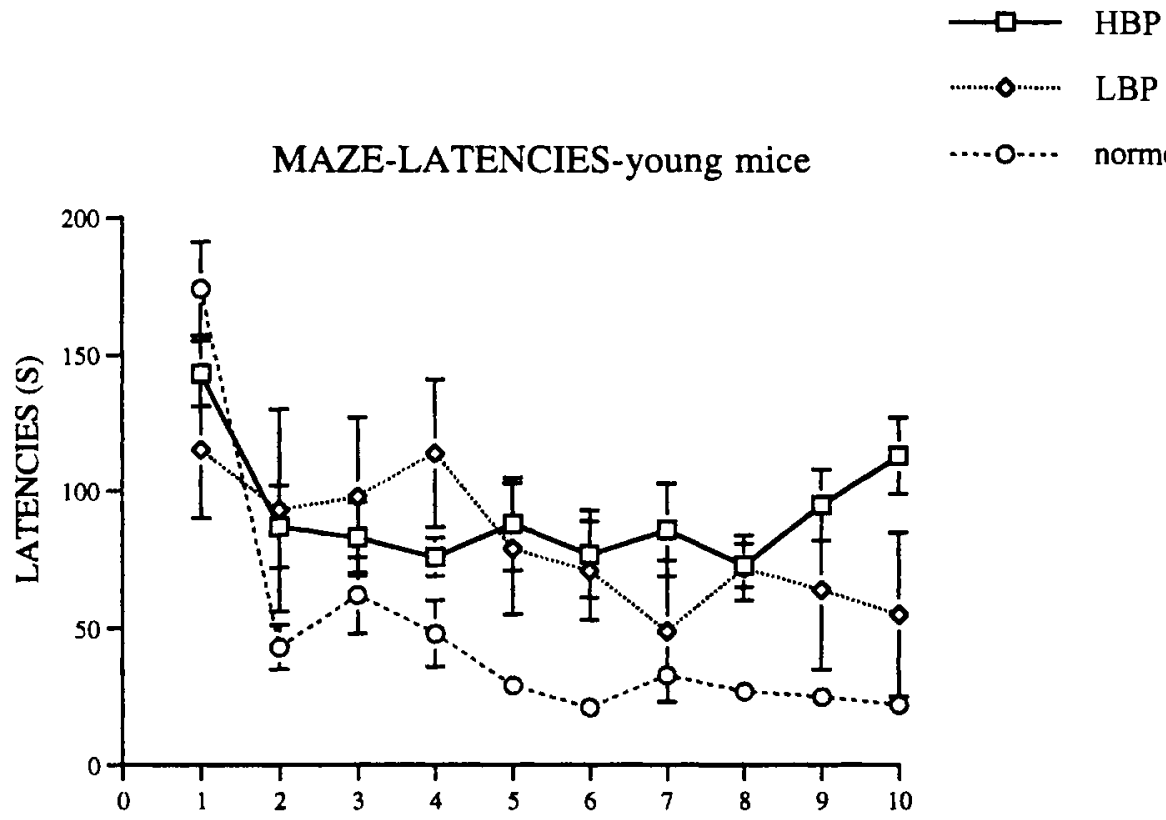

...-0.... normotensive

TRIAL BLOCKS

Figure 4. Quadrant entries and escape latencies in seconds (means and standard errors) in the hidden platform condition of the water maze in young cohorts. HBP, high blood pressure; LBP, low blood pressure. 
Table 4

\begin{tabular}{|c|c|c|c|c|c|c|c|c|}
\hline \multirow[b]{3}{*}{ Groups } & \multicolumn{4}{|c|}{ Invisible Platform } & \multicolumn{4}{|c|}{ Visible Platform } \\
\hline & \multicolumn{2}{|c|}{ Quadrants } & \multicolumn{2}{|c|}{ Latencies } & \multicolumn{2}{|c|}{ Quadrants } & \multicolumn{2}{|c|}{ Latencies } \\
\hline & $M$ & $S E$ & $M$ & $S E$ & $M$ & $S E$ & $M$ & $S E$ \\
\hline \multicolumn{9}{|l|}{12 month old } \\
\hline High blood pressure & 94 & 28 & $179 \dagger$ & 26 & 26 & 3 & 112 & 31 \\
\hline Low blood pressure & 80 & 13 & $216^{\dagger}$ & 12 & 27 & 7 & 113 & 30 \\
\hline Control & 54 & 23 & 70 & 28 & 34 & 6 & 62 & 13 \\
\hline \multicolumn{9}{|l|}{3 month old } \\
\hline High blood pressure & $32^{*}$ & 4 & $78 \dagger$ & 12 & 19 & 3 & $47^{*}$ & 7 \\
\hline Low blood pressure & $33 *$ & 10 & 50 & 16 & $40^{*}$ & 20 & $72 \dagger$ & 43 \\
\hline Control & 16 & 2 & 29 & 4 & 12 & 1 & 16 & 2 \\
\hline
\end{tabular}

activity levels across days of testing, a sign of intersession habituation.

\section{Hole Poking}

In 3-month-old mice, for pokes in the periphery of the hole board (Figure 3), there were significant main factor effects $[F(2,25)=48.42, p<.001$, for groups, and $F(1,25)$ $=11.4, p<.01$, for days], since the LBP mice $(p<.01)$ and the HBP $(p<.05)$ mice had fewer peripheral hole pokes than did the controls. A lower number of pokes was also detected in the center of the board $[F(2,25)=8.67, p<$ .01 ], but only by the LBP mice $(p<.01)$.

In 12-month-old mice, for pokes in the periphery and in the center of the hole board, group effects were found, since the LBP mice, but not the HBP mice, had fewer pokes than did the controls $(p<.01)$.

\section{Water Maze}

For 3-month-old mice, in terms of quadrant entries, a $3 \times 10$ ANOVA ( 3 independent groups, 10 trial blocks) revealed a significant interaction $[F(18,225)=3.25, p<$ $.001]$, since the controls acquired the task faster than did the other two groups (Figure 4). A significant group effect emerged during retention testing $[F(2,25)=5.71$, $p<.01$; Table 4], since the control group traversed fewer quadrants than did the other two groups $(p<.05)$. During visible platform testing (Table 4 ), there was a significant group effect $[F(2,25)=4.04, p<.05]$, since the LBP mice, but not the HBP mice, crossed more quadrants than did the controls $(p<.05)$.

In terms of escape latencies, the interaction was significant $(p<.001)$, since the controls showed evidence of faster learning according to this measure as well (Figure 4). During retention, the escape latencies were higher only in the HBP mice $(p<.01)$. During visible platform testing, the escape latencies of the HBP $(p<.01)$ and the LBP $(p<.05)$ mice were higher than those of the controls.

For 12-month-old mice, in terms of quadrant entries during invisible platform training, a $3 \times 10$ ANOVA ( 3 independent groups, 10 trial blocks) revealed significant effects only for both main factors $[F(2,16)=8.15, p<$ .01 , for groups; $F(9,144)=3.42, p<.001$, for trial blocks]. The control group was superior to the other two groups, the terminal performance of these groups not exceeding Day 1 values and with considerable day-to-day fluctuations in performance (Figure 5). However, no significant group effect emerged during retention testing $[F(2,18)=0.81, p>.1]$, owing, in part, to the poor performance of controls (Table 4). During visible platform testing (Table 4), no intergroup difference was discerned $[F(2,18)=0.74, p>.1]$.

In terms of escape latencies, both main factors and the interaction were significant $(p<.001)$, since the control group reached the hidden platform sooner than did the other two groups, the effect being more potent late in training (Figure 5). During retention, a significant group effect emerged $[F(2,28)=8.73, p<.01]$, since the escape latencies of both experimental groups were higher $(p<$ $.001)$. On the contrary, during visible platform testing, no intergroup difference was observed $[F(2,18)=1.52$, $p>.1]$.

\section{DISCUSSION}

A great variety of behavioral abnormalities were detected in mice with chronic exposure to hypertension or hypotension. HBP mice were hyperactive and were deficient in some aspects of motor coordination and water maze learning. These results indicate the potential value of the HBP mouse as an experimental model of brain dysfunction caused by hypertension. It remains to be determined whether these deficits are directly caused by hypertension. If such is the case, it will be possible to compare between the beneficial effects of various antihypertensive drugs on brain function.

Significant intergroup differences were found in three different facets of exploration behavior-namely, horizontal motor activity, hole poking, and spontaneous alternation. The spontaneous alternation rate of young controls, as for other strains (see, e.g., Lalonde, Joyal, Côté, \& Botez, 1993), was above chance at the shortest retention 


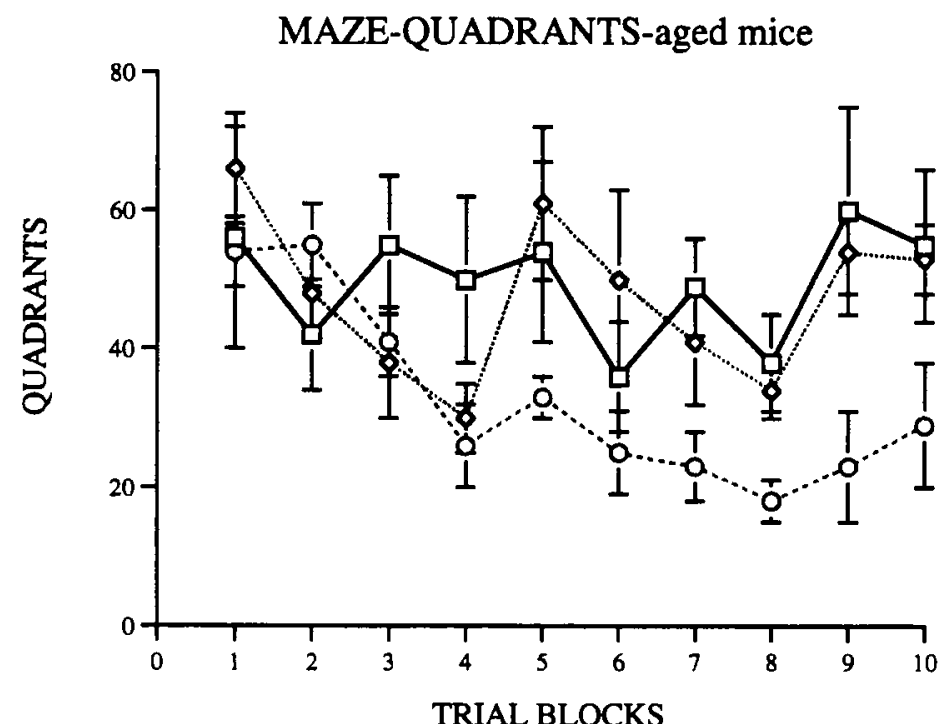

$\longrightarrow$ HBP

MAZE-LATENCIES-aged mice

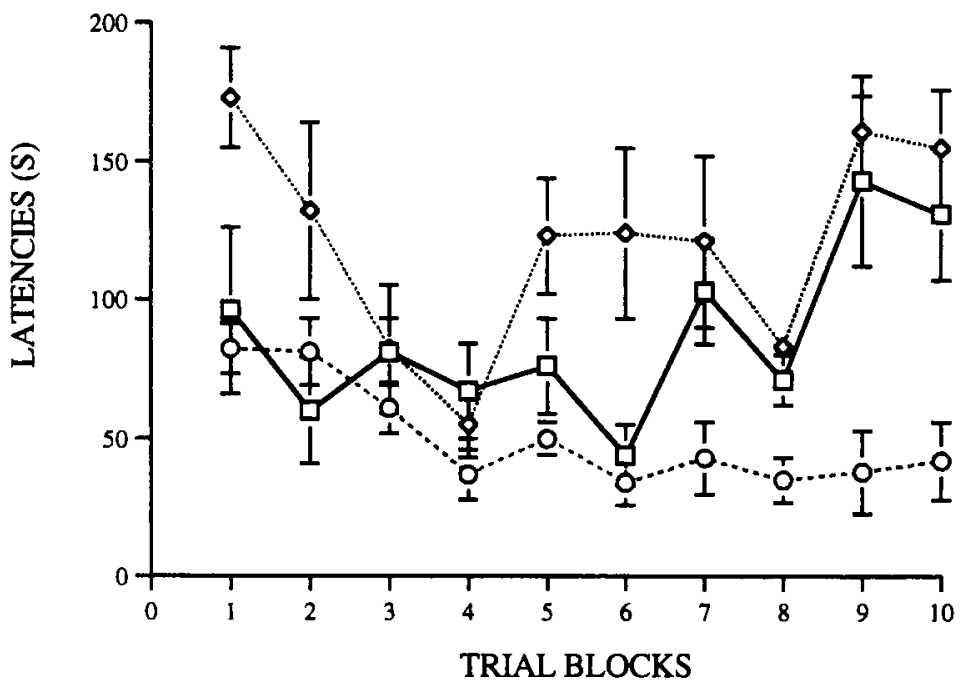

Figure 5. Quadrant entries and escape latencies in seconds (means and standard errors) in the hidden platform condition of the water maze in aged cohorts. HBP, high blood pressure; LBP, low blood pressure.

intervals, indicating a motivation to avoid the most recently explored maze arm and intact spatial or kinesthetic memory. By contrast, the spontaneous alternation rate of old controls was not above chance. Since no alternation was observed even at the shortest retention interval, this result implies an age-associated defect in exploratory tendencies (Lalonde \& Badescu, 1995), rather than in memory.

Irrespective of age, the HBP mice had higher levels of motor activity in the open field and shorter response latencies during spontaneous alternation testing. By contrast, the results in the LBP mice differed according to age. The LBP mice had lower levels of motor activity in the open field and longer response latencies during spontaneous alternation testing than did the controls only at 3 months of age. The age-related decrease of motor activity and the slowing of response speed in the controls were proportionately worse than those of the hypotensive group. Thus, exposure to hypotension at a young age may decrease arousal levels, but this effect is stabilized as a function of time, at least for those animals surviving to middle age. Although we have not formally determined intergroup survival times, it appears that either group 
with abnormal blood pressure has a higher death rate than do controls up to 12 months of age. Therefore, the older cohorts represent the fittest sample of LBP or HBP mice. Nevertheless, the LBP mice had a lower number of hole-poking responses at the periphery and at the center of the hole board than did controls for both young and older age groups. By contrast to general ambulation, hole poking reflects selective attention to specific environmental stimuli.

The hyperactive phenotype of HBP mice reproduces that seen in SHRs (Danysz et al., 1983; Gentsch et al., 1987; Knardahl \& Chindaduangratin, 1984; Leaton et al., 1983; Sagvolden et al., 1992; Whitehorn et al., 1983). There are some indications that hyperactivity is accompanied by lower levels of anxiety in SHRs. For example, Gentsch et al. reported that SHRs had more entries than did Wistar Kyoto rats into a central square of a walled open field and a higher open-arm/total-arm visit ratio in an elevated \pm maze. Moreover, SHRs had shorter latencies before approaching an unfamiliar object placed in the middle of an unfamiliar open field than did Wistar Kyoto rats or Wistar rats (Delini-Stula \& Hunn, 1985). However, there were no intergroup differences in the amount of time spent exploring the novel object and in the number of center crossings in that experiment.

In the present study, HBP mice did not differ from controls in terms of the number of hole pokes in the central part of the hole board. All the groups explored the peripheral part of the hole board more often than the central part, indicative of the typical wall-hugging tendency of mice. On the contrary, a reduction in the number of peripheral hole pokes was observed in the HBP mice at 3 but not at 12 months of age. This hypoexploration is in marked contrast to their increased level of general locomotion in the open field and may be ascribed to impaired selective attention to specific environmental stimuli.

In addition to changes in exploration patterns, deficits of motor coordination were observed in mice with abnormal blood pressure on the inclined grid, coat hanger, and bridge tests. The LBP mice were slower before turning upward and before reaching the top of the inclined grid than were the normotensive controls at 3 months, but not at 12 months of age. Moreover, the shorter latencies before falling from the coat hanger and from the bridge by the LBP mice were limited to 3 months of age. This pattern is similar to that described above for the motor activity and choice latency measures, indicating stabilization of the motor impairment as a function of age. By contrast, the LBP mice had fewer segment crossings on the bridge, irrespective of age. A different pattern of results emerged for latencies before reaching the sidebars on the coat hanger, since the deficit in the LBP mice was only observed in the older cohort. Although longer movement times on the inclined grid and on the coat hanger and a reduction of segment crossings on the bridge may be ascribed to sluggishness, the shorter latencies before falling from the latter two apparatuses indicate postural deficits.
One possibility is that chronic hypotension causes dizziness in these tests. Another possibility is that hypotension causes chronic neurochemical alterations of those brain regions necessary for balance and equilibrium, despite the absence of neurological signs, such as ataxia. Shorter latencies before falling were also observed in the HBP mice, but this impairment was limited to the bridge test and only for the older animals. Nevertheless, despite normal latencies before falling, the HBP mice traversed fewer segments on the bridge and had longer movement times on the coat hanger at a young age. These deficits cannot be ascribed to hypoarousal, since the same mice were hyperactive in the open field. Instead, these results indicate deficits of motor coordination, despite the absence of ataxia or tremor.

In the young cohort, the LBP mice were impaired, relative to the controls, on both the hidden and the visible platform versions of the water maze. By contrast, in the older cohort, their impairment was limited to the hidden platform version. Thus, in a similar fashion to motor activity and to some measures of motor coordination, the navigational deficit in hypotensive mice appears early and is not aggravated during the course of aging. It remains to be determined whether these neurobehavioral abnormalities are directly attributable to hypotension or to altered genes independent of those controlling blood pressure.

As in the LBP mice, differential effects in terms of aging were observed for the HBP mice in the water maze task. Visible platform performance was impaired in the HBP mice only at a young age, whereas acquisition of the hidden platform version was impaired at either age. The visible platform impairment was limited to escape latencies and did not apply to distance traveled, which is indicative of slowed responding. By contrast, both quadrant entries and escape latencies were higher than those for the controls during spatial learning, which is indicative of a directional deficit. It is possible that chronic exposure to hypertension causes abnormalities in those brain regions implicated in place learning, such as the hippocampus (Morris et al., 1982) or the cerebellum (Goodlett et al., 1992; Lalonde, 1987). On the other hand, Elias and Schlager (1974) determined that those genes responsible for the poor performance of HBP mice in a two-arm maze task were not the same as those responsible for causing hypertension. We intend to pursue this inquiry by determining the genetic basis of the spatial deficits in these mice.

\section{REFERENCES}

BENDEL, P., \& EILAM, R. (1992). Quantitation of ventricular size in normal and spontaneously hypertensive rats by magnetic resonance imaging. Brain Research, 574, 224-228.

Danysz, W., Plaznik, A., Pucilowsky, O., Plewako, M., OberszTYN, M., \& KostowsKI, W. (1983). Behavioral studies in spontaneously hypertensive rats. Behavioral \& Neural Biology, 39, 22-29.

Delini-Stula, A., \& HunN, C. (1985). Neophobia in spontaneous hypertensive (SHR) and normotensive control (WKY) rats. Behavioral \& Neural Biology, 43, 206-211. 
Elias, M. F., \& Schlager, G. (1974). Discrimination learning in mice genetically selected for high and low blood pressure: Initial findings and methodological implications. Physiology \& Behavior, 13, 261267.

Gentsch, C., Lichtsteiner, M., \& FeER, H. (1987). Open field and elevated plus-maze: A behavioural comparison between spontaneously hypertensive (SHR) and Wistar-Kyoto (WKY) rats and the effects of chlordiazepoxide. Behavioural Brain Research, 25, 101-107.

GoodletT, C. R., HAMre, K. M., \& WEST, J. R. (1992). Dissociation of spatial navigation and visual guidance in Purkinje cell degeneration (pcd) mutant mice. Behavioural Brain Research, 47, 129-141.

Hamet, P., Richard, L., Dam, T.-H., Teiger, E., Orlov, S. N. Gaboury, F., \& TrEmblay, J. (1995). Apoptosis in target organs of hypertension. Hypertension, 26, 642-648.

HenRy, J. P., Liu, J., \& Meehan, W. P. (1995). Psychosocial stress and experimental hypertension. In J. H. Laragh \& B. M. Brenner (Eds.), Hypertension: Pathophysiology, diagnosis, and management (pp. 905 921). New York: Raven Press.

Iwao, H., Nakamura, N., Kim, S., Ikemoto, R., Yamamoto, K., \& SCHLAGER, G. (1984). Renin-angiotensin in genetically hypertensive mice. Japanese Circulation Journal, 48, 1270-1279.

Knardahl, S., \& Chindaduangratin, C. (1984). Residential-maze behavior of spontaneously hypertensive rats. Behavioral \& Neural Biology, 41, 84-89.

KNARDAHL, S., \& KarLSEN, K. (1984). Passive-avoidance behavior of spontaneously hypertensive rats. Behavioral \& Neural Biology, 42 , 9-22.

LALONDE, R. (1987). Exploration and spatial learning in staggerer mutant mice. Journal of Neurogenetics, 4, 285-292.

LALONDE, R., \& BADESCU, R. (1995). Exploratory drive, frontal lobe function and adipsia in aging. Gerontology, 41, 134-144.

Lalonde, R., Joyal, C. C., Côté, C., \& Botez, M. I. (1993). Delayed spontaneous alternation in lurcher mutant mice. Psychobiology, 21, 139-141.

Leaton, R. N., Cassella, J. V., \& Whitehorn, D. (1983). Locomotor activity, auditory startle and shock threshold in spontaneously hypertensive rats. Physiology \& Behavior, 31, 103-109.

LiNEs, C. R., \& MilNER, A. D. (1985). A deficit in ambient visual guidance following superior colliculus lesions in rats. Behavioral Neuroscience, 99, 707-716.

Malo, D., Pang, S. C., Schlager, G., Tremblay, J., \& Hamet, P. (1990). Decrease of blood pressure in spontaneously hypertensive mice by heat treatment. American Journal of Hypertension, 3, 400404.

Malo, D., Schlager, G., Tremblay, J., \& Hamet, P. (1989). Thermosensitivity, a possible new locus involved in genetic hypertension. Hypertension, 14, 121-128.

MCCARTY, R. (1983). Stress, behavior and experimental hypertension. Neuroscience \& Biobehavioral Reviews, 7, 493-502.

Meneses, A., \& Hong, E. (1998). Spontaneously hypertensive rats: A potential model to identify drugs for treatment of learning disorders Hypertension, 31, 968-972.

Morris, R. G. M., Garrud, P., RaWlins, J. N. P., \& O'KeEFe, J. (1982). Place navigation impaired in rats with hippocampal lesions. Nature, 292, 681-683.

RitTer, S., \& DiNH, T. T. (1986). Progressive postnatal dilation of brain ventricles in spontaneously hypertensive rats. Brain Research, 370, 327-332.

RitTer, S., Dinh, T. T., Stone, S., \& Ross, N. (1988). Cerebroventricular dilation in spontaneously hypertensive rats (SHRs) is not attenuated by reduction of blood pressure. Brain Research, 450, 354-359.

Sagvolden, T., Hendley, E. D., \& KNaRdahl, S. (1992). Behavior of hypertensive and hyperactive rat strains: Hyperactivity is not unitarily determined. Physiology \& Behavior, 52, 49-57.

Saito, N., Noda, K., Yamasaki, Y., Matsubayashi, K., OKada, T., \& NishiYama, S. (1992). Cataracts in hypertensive rats. In J. Sassard (Ed.), Genetic hypertension (pp. 413-415). London: John Libbey Eurotext.

SCHLAGER, G. (1974). Selection for blood pressure levels in mice. $G e$ netics, 76, 537-549.

SCHLAGER, G. (1981). The genetically hypertensive mouse. Trends in Arterial Hypertension, 17, 321-331.

Schlager, G., Freeman, R., \& Sustartic, S. S. (1979). Brain catecholamines and organ weight of mice genetically selected for high and low blood pressure. Experientia, 16, 67-69.

StewarT, J. D., Bray, G. M., \& Aguayo, A. J. (1983). Diseases of the autonomic nervous system. In R. N. Rosenberg (Ed.), The clinical neurosciences (pp. 503-527). London: Churchill Livingstone.

Sutherland, R. J., \& Rodriguez, A. J. (1989). The role of the fornix/fimbria and some related subcortical structures in place learning and memory. Behavioural Brain Research, 37, 57-79.

Whitehorn, D., Atwater, D. G., Low, W. C., Gellis, J. E., \& HendLEY, E. D. (1983). Independence of blood pressure and locomotor byperactivity in normotensive and genetically hypertensive rat. Behavioral \& Neural Biology, 37, 357-361.

WIDY-TySzKIEWICZ, E., SChEel-Krüger, J., \& Christensen, A. V (1993). Spatial navigation learning in spontaneously hypertensive, renal hypertensive and normotensive Wistar rats. Behavioural Brain Research, 54, 179-185.

Wyss, J. M., FISK, G., \& VAN GroEN, T. (1992). Impaired learning and memory in mature spontaneously hypertensive rats. Brain Research, 592, 135-140.

YAMORI, Y. (1983). Physiopathology of the various strains of spontaneously hypertensive rats. In J. Genest, O. Kuchel, P. Hamet, \& M. Cantin (Eds.), Hypertension (2nd ed., pp. 556-581). New York: McGraw-Hill.

(Manuscript received August 14, 1998; revision accepted for publication February 12, 1999.) 